\title{
Los legados suntuarios de Juan Rodríguez de Fonseca. El terno de San Isidoro de León
}

\author{
María Dolores Teijeira Pablos \\ Universidad de León
}

\section{RESUMEN:}

Juan Rodríguez de Fonseca, obispo de varias sedes castellanas y hombre de estado al servicio de la corona en los últimos años del siglo XV y primeros del XVI, fue un importante patrón artístico en los templos de los que fue titular, promoviendo relevantes obras de arquitectura, escultura y pintura en ellos, y regalando, o legando en su testamento, significativas piezas suntuarias, especialmente vestiduras litúrgicas. Como abad de San Isidoro de León legó a esta casa un terno que todavía se conserva y que se estudia ahora por primera vez, como muestra de su interés por el correcto, y esplendoroso, desarrollo del culto en sus iglesias.

\section{ABSTRACT:}

Juan Rodríguez de Fonseca, a bishop on different castilian sees and stateman on the service of the kings in the last years of XVth century and the beginning of XVIth century, was an important artistic patron for his churches. He promoted significant works or architecture, sculpture and painting on them, and offered, or left in his will, outstanding sumptuary objects, especially liturgic vestments. As the abbot of San Isidoro de León he bequeathed to this monastery a vestment, preserved but not considered until now, as a proof of his interest on the accurate, and splendorous, development of the worship in his churches.

\section{PALABRAS CLAVE:}

Juan Rodríguez de Fonseca, San Isidoro de León, Vestidura litúrgica, Patronazgo artístico.

\section{KEY WORDS:}

Juan Rodríguez de Fonseca, San Isidoro de León, Liturgic vestment, Artistic patronage. 
Juan Rodríguez de Fonseca (1451-1524), obispo de Badajoz, Córdoba, Palencia y Burgos, arzobispo de Rossano y embajador y gestor al servicio de los Reyes Católicos y Carlos I en su política europea y americana, fue también un patrón artístico enormemente importante en su época, como esta, a caballo entre el final del gótico y los inicios de la implantación del modelo renacentista en Castilla, dejando obras tan significativas de uno y otro estilo como el trascoro de la catedral palentina y la escalera dorada de la catedral burgalesa, sedes ambas de las que fue titular ${ }^{1}$.

Sus intereses artísticos cubrieron un amplio abanico de tipologías, desde la promoción arquitectónica hasta el encargo y donación de piezas suntuarias, siempre contando con los mejores artistas que tenía a su alcance y promoviendo obras que tanto material como artísticamente presentaran la mayor calidad posible.

Fonseca mostró siempre un gran interés por los objetos lujosos, tanto para su uso personal como en forma de regalos a aquellas instituciones y personas con las que tuvo una relación más estrecha. Tanto en uno como en otro caso, al gusto personal por este tipo de objetos se uniría el deseo de ostentación de quien se consideraba un personaje relevante, tanto por su pertenencia a un determinado linaje como por los diferentes cargos que fue asumiendo. Por otra parte, a lo largo de toda su carrera eclesiástica mostró una preocupación importante por el correcto desarrollo de la actividad religiosa en aquellas sedes, o casas religiosas, que

1 El papel de Fonseca como comitente artístico se basa en TEIJEIRA PABLOS, María Dolores, "De Badajoz a Burgos. Juan Rodríguez de Fonseca en sus catedrales" elaborado en el marco de desarrollo del Proyecto de Investigación "El patronazgo artístico en el reino de Castilla y León (1230-1500). Obispos y catedrales". Ref. HAR2013-44536-R, financiado por el Ministerio de Economía y Competitividad y fondos FEDER, y que se publicará en Laboratorio de Arte, 29, Sevilla, 2017, pp. 53-82. Me remito a este texto para la bibliografía básica y el estado de la cuestión acerca de esta figura, así como a los textos, ya clásicos, de YARZA LUACES, Joaquín, "Dos mentalidades, dos actitudes ante las formas artísticas: Diego de Deza y Juan Rodríguez de Fonseca (1500-1514)", en Jornadas sobre la catedral de Palencia, Universidad de verano Casado del Alisal, Valladolid, 1989, pp.105-142 y REDONDO CANTERA, María José, “Juan Rodríguez de Fonseca y las artes”, en SAGARRA GAMAZO, Adelaida (ed.), Juan Rodríguez de Fonseca: su imagen y su obra, Universidad de Valladolid, Valladolid, 2005, pp.175-206. El presente artículo se ha elaborado también en el marco del mismo proyecto anteriormente citado. rigió, cuidando de que tuvieran las infraestructuras y los recursos necesarios para ello. De este modo se ocupó de la finalización de la catedral palentina y la adecuación de sus espacios, de la adaptación del acceso septentrional de la catedral burgalesa y de la dotación de los ornamentos y objetos que posibilitaran la actividad litúrgica, tanto en vida como en sus legados testamentarios ${ }^{2}$. En este sentido siguió el ejemplo de otros patronos eclesiásticos, entre ellos el de su tío Alonso de Fonseca, con el que se formó, que había donado al monasterio de la Mejorada de Olmedo, "un hornamento complido, capa, casulla, almáticas y frontal de carmesí hecho de labores", aparte de otros bienes artísticos ${ }^{3}$, es decir un conjunto completo de vestiduras eclesiásticas formado por el habitual terno -casulla para el celebrante y dos dalmáticas para los diáconos-, enriquecido con la capa pluvial y acompañado del habitual frontal de altar a juego con el terno, todo ello "de carmesí, uno de los colores litúrgicos más habituales, y "hecho de labores", es decir con motivos tejidos o bordados que indican una obra compleja y rica.

En vida Fonseca regaló a la catedral de $\mathrm{Pa}-$ lencia un terno de brocado altibajo que recoge el arcediano del Alcor en su Silva palentina ${ }^{4}$, y

2 El testamento de Juan Rodríguez de Fonseca se conserva, en copia manuscrita del siglo XIX, en el Archivo ducal de Alba. Sección de Patronato. A.A. c.342-1/7 (en adelante Testamento). Es depósito del hospital de Toro, principal beneficiario del legado del obispo. Quiero agradecer a José Manuel Calderón, director del Archivo, el haberme proporcionado copia de dicho documento.

3 El texto se encuentra en una crónica de la Mejorada, escrita en la segunda mitad del siglo XVI, citada en ARIAS MARTÍNEZ, Manuel, "Sobre el retablo de San Jerónimo del pintor Jorge Inglés”, en Boletín del Museo Nacional de Escultura, 1, Valladolid, 1996-1997, p.10.

$4 \quad$ El arcediano del Alcor incluye en esta obra el siguiente documento: "Miércoles XII de noviembre de 1522, el señor licenciado Gregorio del Castillo, canónigo, traxo y entregó a los dichos señores deán y cabildo, capitularmente juntos en su capilla capitular, un ornamento rico que le auía dado para que traxese a los dichos señores para la dicha yglesia el ylustre y reverendísimo señor don Juan Rodríguez de Fonseca, obispo de Burgos y que primero lo fue de Palencia, en el qual ornamento auía una casulla e dos almáticas con sus collares ricos e su capa con su capilla, todo de brocado...e con sus cenefas e cordones e sus escudos de armas de cinco luceros, que son del dicho señor obispo, e los dichos señores lo recibieron e dieron por ello muchas gracias a Dios e al dicho señor obispo, e mandáronlo leuar a la sacristía, e que se escriuiesse en el libro de los otros ornamentos, e cosas de la dicha yglesia, e ordenaron e mandaron que luego se dixese una misa solene con el dicho ornamento por la saluz e vida del dicho señor 
que no se conserva ${ }^{5}$. Como describe el arcediano, el ornamento, donado a la catedral palentina en la época en que Fonseca era ya obispo de Burgos, estaba formado por el terno -casulla y dos dalmáticas- y la capa pluvial con su capillo. El conjunto, de brocado altibajo ${ }^{6}$, es decir con motivos en relieve, debía ser lujoso, como señala la descripción, con las correspondientes cenefas, destacando la presencia, habitual en los encargos del obispo, de su escudo "de cinco luceros", es decir el del linaje Fonseca formado por cinco estrellas de gules en sotuer en campo de oro ${ }^{7}$.

A la catedral de Burgos entregó, supuestamente también en vida, unas casullas y dalmáticas que no se han conservado ${ }^{8}$. Además, a esta su última sede, la de Burgos, a la que llegó en 1514 y donde permaneció hasta su muerte, legó en testamento un lujoso ornamento de plata bordado en oro, también formado por capa y capilla, casulla, dalmáticas, además de frontal y frontaleras. Este ornamento no es un legado testamentario sin más, sino que obedece al deseo del obispo de compensar tras su muerte una obligación contraída e incumplida involuntariamente en vida "ansí por el amor que en la dicha iglesia tenemos como por mayor descargo de nuestra conciencia, para satisfación de los frutos que de ella e de nuestra mesa obispal hemos llevado".

obispo". FERNÁNDEZ DE MADRID, Alonso, Copilación o catálogo de los ouispos que por escrituras antiguas allamos auer precedido en la yglesia de Palencia con algunas concurrencias notables que en tienpo de cada vno acaecieron (Silva palentina), Ed. de Imprenta de “El Diario palentino", Palencia, 1932 T.II, p.74, nota 1. De este ornamento dice ÁLVAREZ REYERO, Antonio, Crónicas episcopales palentinas, Imprenta de Abundio Menéndez, Palencia, 1898, p.209, que "lleva su nombre", en alusión quizá a su escudo.

5 Matías Vielva Ramos, que anota la edición de la Silva publicada en 1932, dice que ya no se conservaba, y que debía ser de los que, entre los siglos XVIII y XIX, se desecharon por inservibles. FERNÁNDEZ DE MADRID, Alonso, Silva palentina. opus cit., p. 74, nota 1.

6 GARRACHÓN BENGOA, Ambrosio, La catedral de San Antolin, Imprenta de "El Diario palentino", Palencia, 1921, p.67.

7 Juan Rodríguez de Fonseca utilizaba tanto el escudo familiar como el personal, en este último caso cuartelado y con las armas de las dos líneas paterna y materna -Fonseca, Ulloa, Ayala y Cervantes-. En los ornamentos que conocemos, bien por la propia obra, bien por descripción, usó únicamente el familiar.

8 REDONDO CANTERA, María José, Juan Rodríguez de Fonseca. opus cit., p. 2040.

9 Testamento, cláusula 48.
La mayoría de este tipo de objetos suntuarios procede, como este último, y como sucede también en el caso de la orfebrería religiosa, de legados testamentarios a los templos por los que pasó a lo largo de su dilatada carrera religiosa. A sus sedes episcopales, aparte del legado burgalés anteriormente comentado, dejó otro para Córdoba, de la que fue obispo entre 1499 y 1504: un ornamento de damasco carmesí con motivos de alcachofas, formado por las habituales capa, casulla y dalmáticas, además de estola y manípulos. Como otros ornamentos incluidos en su última voluntad, este no estaba acabado, ya que parece faltar la cenefa de la casulla "que la está haciendo Cornilles"10. Ningún recuerdo tuvo para su primera sede, Badajoz (1495-1499), con la que tuvo siempre una relación conflictiva.

También en su testamento incluyó otras casas religiosas que estuvieron bajo su dirección, a pesar de que en vida no pareció preocuparse excesivamente por ellas, ejerciendo su papel de abad comendatario como era habitual en la época, sólo como medio de procurarse más rentas y acaparar más cargos. Sin embargo, si bien es verdad que algunas se quejaban de que el abad se llevaba las rentas y no hacía nada en beneficio de la casa, como sucede en el caso de San Zoilo de Carrión ${ }^{11}$, parece evidente que con otras sí tuvo una relación más cercana; debió ser el caso de Santa María de Párraces -o Parrales- (Segovia), a cuya iglesia legó un terno (capa, casulla y dos dalmáticas) de tela de oro con cenefa de terciopelo azul, que estaba incompleto, como en el caso anterior, ya que sólo estaba hecha la casulla ${ }^{12}$.

Además, a la iglesia de Santa María de Coca, lugar de su enterramiento y panteón familiar, dejó varios ornamentos importantes, tanto para uso normal de la iglesia, como -los más ricospara su propio beneficio espiritual, en el sentido de que en el mismo testamento se establece que sólo puedan usarse en determinados ser-

\footnotetext{
10 Testamento cláusula 12.

1 Tras la muerte de Fonseca, el rey Fernando pidió a sus familiares que dieran algo de las rentas que había dejado para arreglar el arruinado monasterio, cuya iglesia estaba a punto de caerse. ZARAGOZA PASCUAL, Ernesto, "Abadologio del monasterio de San Zoilo de Carrión de los Condes (siglos XI-XIX) y Libro de Gradas de los monjes que profesaron en el (1593-1833)", en Publicación de la Institución Tello Téllez de Meneses, 64, Palencia, 1993, p. 286.

12 Testamento, cláusula 50.
} 
vicios litúrgicos relacionados con la memoria propia y la génerica de la familia ${ }^{13}$.

Legó también sendas casullas de seda para los monasterios burgaleses de Palacios de Benagel (Benaver?) y Ausin' ${ }^{14}$, con los que no sabemos qué relación pudo haber tenido, si bien a este último le legó también 100 reales para reparo de la casa ${ }^{15}$. Al final de su codicilo dejó también vestiduras y objetos litúrgicos de su cámara para repartir entre las parroquias pobres de la diócesis de Burgos, de la que era obispo en el momento de su muerte.

\section{El terno de San Isidoro de León}

En 1519, siendo obispo de Burgos y arzobispo de Rossano, Fonseca se convirtió en abad comendatario de San Isidoro de León, cargo que mantendría hasta su muerte. Seguramente el acceso al cargo de abad se debiera a su interés por acumular cargos y rentas, como en los casos de Párraces y San Zoilo de Carrión. No hay noticia alguna que indique un interés especial por esta obra, ni siquiera que hubiera estado alguna vez en León, a pesar de que a finales de 1520 hubo de pasar por la ciudad, o cerca de ella, ya que, en el contexto de las Comunidades, y debido a que se le acusaba de haber participado en el incendio de Medina del Campo, tuvo que huir de Burgos. En su huida, y puesto que no encontró apoyo en su diócesis, intentó llegar a Santiago de Compostela, de donde era arzobispo su primo Alonso de Fonseca. Antes de llegar a Santiago el marqués de Astorga le acogió y protegió y pasó en Astorga los meses siguientes, hasta que pudo volver a Burgos en paz $^{16}$. En cualquier caso no hay constancia de

13 En concreto legó un ornamento completo de terciopelo negro con calaveras para las misas de réquiem y otro, también negro, que estaba incompleto en el momento de su muerte, además de otros más sencillos para diario y un último heredado de su tío Alonso de Fonseca. En varios de ellos se cita la presencia de su escudo. Testamento, cláusulas 9-11.

14 Testamento, cláusula 53.

15 Testamento, cláusula 25.

16 En un primer momento se refugió en Villafruela, de donde hubo de huir también ante la inminencia de un ataque, viajando sin parar ante la falta de alguien que quisiera darle cobijo, como relata en la carta que le envió al emperador en enero de 1521 desde Astorga. DANVILA COLLADO, Manuel, Historia crítica y documentada de las comunidades de Castilla, Imprenta de la viuda e hijos de M. Tello, Madrid, 1897, T.III, pp.134136. SALVÁ, Anselmo, Burgos en las comunidades de que en esos meses estuviera en León o que tuviera contacto de algún tipo con San Isidoro, aunque tampoco puede descartarse.

La única información que tenemos sobre la relación de Fonseca con San Isidoro es la proporcionada por Pérez Llamazares ${ }^{17}$, basándose en textos antiguos conservados en la colegiata, entre ellos las crónicas de los canónigos quinientistas Juan de Villafañe ${ }^{18}$ y Juan Durón ${ }^{19}$, quienes, con escasas variantes, dan algunos datos básicos sobre Fonseca ${ }^{20} \mathrm{y}$, de su relación con San Isidoro, dicen:

"Era muy affiçionado a los religiosos de esta Casa, tratábalos amorosa y mansamente. Dio para començar la claustra çincuenta mil maravedís y el terno de carmesí altiuaxo con las armas de los Fonsecas. En él daba entender de su buena voluntad que abya de hazer buenas obras a esta Casa si viuiera y ansí se esperaba del"21.

A partir de estas noticias se ha estudiado en ocasiones la obra del claustro, que sería una cubierta de ladrillo del claustro románico, edificación que sólo dos siglos más tarde estaría

Castilla, Imprenta y Librería de Hijos de Santiago Rodríguez, Burgos, 1895, cap. XIV. El 20 de octubre de 1520 se leyó en el cabildo de Burgos una carta del obispo, entonces en Astorga, en la que pedía que se hablara con los procuradores de la ciudad para excusarle de la culpa que se le atribuía en el incendio de Medina. Archivo Capitular de Burgos (ACB). Libro Registro 41, fol.54r. En marzo de 1521 aún no había vuelto. Libro Registro 39, fol.171r.

17 PÉREZ LLAMAZARES, Julio, Historia de la Real Colegiata de San Isidoro de León, Imprenta Moderna, León, 1927, p.184. Del mismo autor ver también El tesoro de la Real Colegiata de San Isidoro de León, Imprenta y Librería religiosa, León, 1925. En esta obra se cataloga como terno VII.

18 VILLAFAÑE, Juan de, Libro manuscripto sobre los estados que ha tenido esta Real Casa de San Ysidro de León, 1553. Archivo de San Isidoro de León (ASIL), Códice 92. La parte dedicada a Juan Rodríguez de Fonseca se encuentra en el capítulo 20, fol. 29v.

19 DURÓN, Juan, La fundación y sucessos del Monasterio de San Isidoro de León compuesta por el bachiller Durón canónigo reglar del mismo monasterio, 1592. ASIL, Códice 91. La parte dedicada al abad Fonseca se encuentra también en el Capítulo 20, fols. 121v.-122r.

20 "El 28 (abad) fue Don Joan Rodríguez de Fonseca Arçobispo de Rosano y Obispo de Burgos commandatario de Nuestra Señora de Parraces / y San Zoil de Carrión. El qual no contentándose con las Quatro prelacias procuro de aber y vbo la Abbadia desta nuestra casa pidiéndola al dicho Obispo Don Gomez de Toledo con cierta pensión que le dio, fue administrador y commendatario algunos años”. ASIL, Códice 92, fol. 29v.

21 Ibídem. 
ruinosa y sería sustituida por el claustro actual $^{22}$.

El terno es mucho más desconocido, y aparte de la noticia mencionada apenas hay más datos que permitan conocerlo. La obra constituye el legado testamentario de Fonseca para San Isidoro de León, recogiéndose en el testamento su donación en los siguientes términos:

"Item mandamos a nuestro monasterio de Sancto Isidro de León una casulla y dos almáticas de altibajo carmesí, las almáticas con sus faldones y bocas de manga bordadas e sabastros y la casulla se ha de poner cenefas conforme al ornamento"23.

Según este documento el ornamento estaba originalmente formado sólo por la casulla -inacabada- y las dos dalmáticas, lo que supone que las piezas restantes se hicieron con posterioridad y no estaban incluidas entre las intenciones de patronazgo de Fonseca, aunque siguieron las líneas generales del conjunto.

Aparte de estas escasas noticias documentales conservamos la propia obra, si bien en un estado de conservación bastante pobre, sobre todo por lo que respecta a alguna de sus piezas.

El terno está formado en realidad por cinco piezas: una capa pluvial, dos dalmáticas, una casulla y un paño de facistol. Ademas del escudo de Fonseca, el de la orden agustiniana y el del monasterio, las dalmáticas y los paños de facistol llevan la fecha de 1566, lo que indicaría que o bien estas piezas se hicieron más tarde 0 bien se restauraron o completaron entonces. ${ }^{24}$

Todas las piezas están hechas de terciopelo carmesí altibajo (con motivos florales en relieve, de dos altos -motivo y fondo-), con orlas, remates y apliques bordados en hilo de oro y seda. Las fichas de inventario del terno que

22 MORAIS VALLEJO, Emilio, "Reinas e infantas en la decoración escultórica del claustro basilical de San Isidoro de León”, en Estudios Humanísticos. Geografía, Historia y Arte, 22, León, 2001, pp. 211-230, especialmente 211-213. El crítico estado de conservación en que se encontraba, confirmado por los informes técnicos emitidos en 1728 por dos arquitectos, determinaron la construcción del claustro actual, si bien la panda adosada a la iglesia no fue reconstruida.

23 Testamento, cláusula 51.

24 El terno está inventariado en los fondos del Museo con el número IIC-3-089-002-0361-001 (001 para la capa, 002 para la casulla, 003 para las dalmáticas y 004 para el paño de facistol, dos según la ficha). Agradezco a $\mathrm{D}^{\mathrm{a}}$ Raquel Jaén y D. Luis García, directores del Museo de San Isidoro su disposición y amabilidad al permitirme ver y fotografiar las piezas. conserva el Museo de San Isidoro consideran que la capa se hizo usando un terciopelo diferente del de dalmáticas y casulla, pero también que, puesto que las dalmáticas y los paños de facistol llevan la fecha de 1566 y parecen haber utilizado un tipo diferente de bordado, éstas serían piezas posteriores al resto. En realidad, a la vista del texto del testamento, el legado estaría realmente formado por el terno clásico -casulla y dos dalmáticas-, pudiéndose hacer el resto con posterioridad, quizá por encargo del propio monasterio, para completar y hacer más monumental el ornamento.

Sin duda la pieza más lujosa del terno es la capa pluvial (Fig. 1). Elaborada en terciopelo carmesí, con el mismo dibujo en relieve que el resto de las piezas, destaca por la riqueza del capillo y de la ancha cenefa bordada que remata su borde.

El capillo (Fig. 2), de forma cuadrangular, curvada en la parte inferior y rematada en punta como los escudos de tradición gótica usados habitualmente en la Castilla tardogótica, entre otros por el propio Fonseca, está hecho sobre un paño dorado cuyo ligamento va dibujando motivos vegetales y que se enmarca con una estrecha franja de hilo de oro llano, formando cuadrícula. Representa la Asunción de la Virgen, devoción personal del obispo, apareciendo María acompañada de seis ángeles, tres de cada lado, que sujetan su manto a la altura de las piernas, los brazos y los hombros. Los contornos de las figuras están realizados a punto de pespunte y cordoncillo de oro para las zonas de mayor relieve y movimiento, mientras que los rellenos, sombras, detalles y efectos de modelado aparecen en punto de matiz. Las zonas de carne (rostros, manos y brazos, piernas) están sobrepuestos, en fina seda color beige, con las sombras, modelados y rasgos bordados en las habituales técnicas de encarnación. Los colores utilizados para todos estos detalles acentúan el tono dorado del fondo y la orla de remate, al usarse diversos tonos de ocre y colores fríos como el azul y el verde.

En cuanto al orifrés o cenefa de remate de la capa está formado por la continuidad de seis capilletas, todas ellas con un mismo formato y similar técnica a la vista en el capillo -paño dorado, bordado con diversos puntos de figura y sobrepuestos también bordados-: bajo un arco de medio punto rebajado se desarrolla una escena, que ocupa aproximadamente los dos tercios del registro, apareciendo, en el tercio 


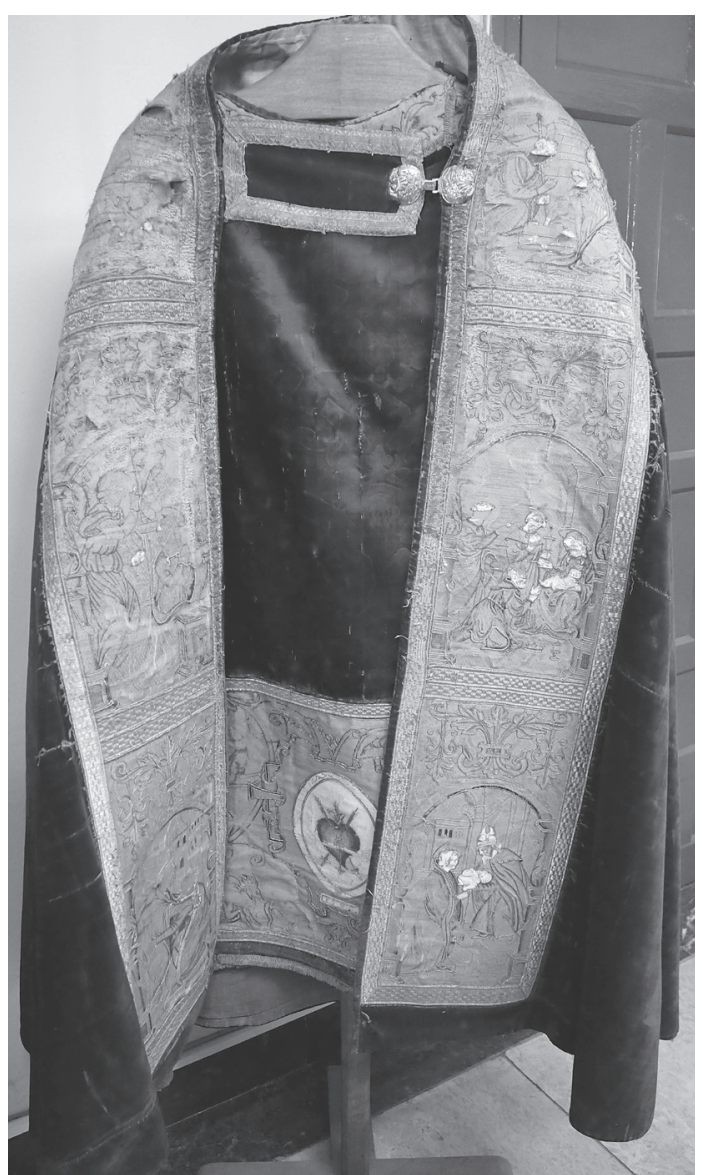

Fig. 1. Capa pluvial y dalmática del terno de Juan Rodríguez de Fonseca. San Isidoro de León. Ca. 1525-1566. Foto de la autora.

superior, sobre el arco, un mismo motivo a base de elementos vegetales desarrollados de manera simétrica. Las escenas incluidas pertenecen todas al ciclo de la Vida de la Virgen (lado derecho) y de la infancia de Cristo (lado izquierdo) y se leen de arriba abajo, estando la capa sobre los hombros del oficiante y comenzando por el lado derecho: Presentación de María en el templo -arriba a la derecha-, Anunciación -centro a la derecha-, Visitación -abajo a la derecha-, Nacimiento -arriba a la izquierda-, Adoración de los Magos -centro a la izquierday Presentación del Niño en el templo -abajo a la izquierda-. Por desgracia la capa es la pieza del terno que se encuentra en peor estado, afectando el deterioro, sobre todo, a los bordados de la cenefa de remate, en la que las escenas de la parte derecha han perdido ya todos los sobrepuestos y gran parte de los dintornos, que se conservan en muy mal estado en la parte izquierda, siendo la escena de la Presentación del niño la que se encuentra en mejor estado y

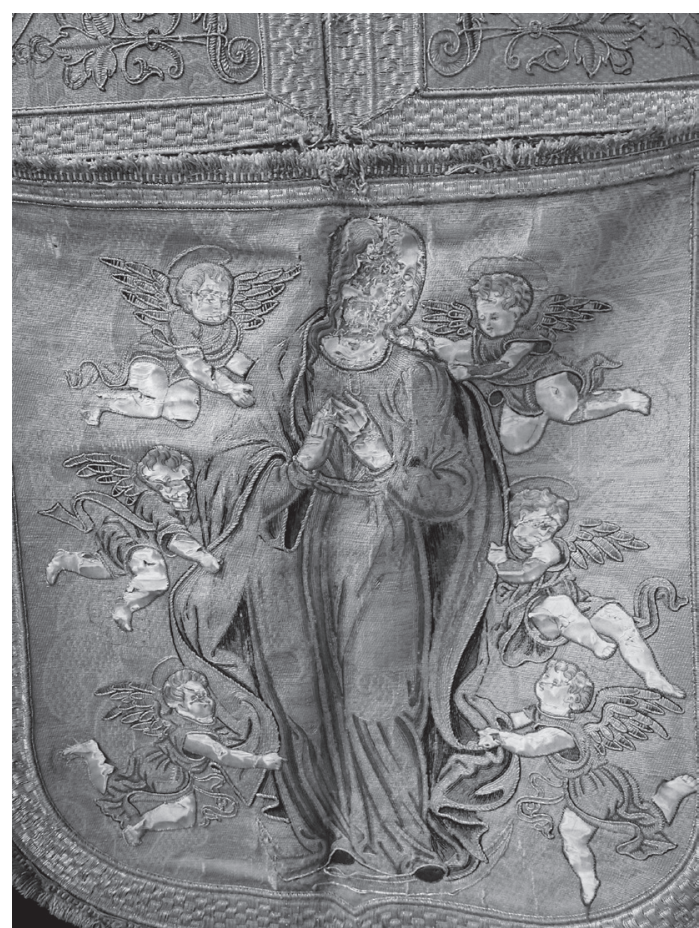

Fig. 2. Capillo de la capa pluvial del terno de Juan Rodríguez de Fonseca. San Isidoro de León. Ca. 1525-1566. Foto de la autora.

puede darnos una idea de la riqueza y finura de los materiales y técnicas empleados (Fig. 3). El modelo de capa y su iconografía es similar a la que lleva el propio Fonseca en el remate de la Puerta de la Pellejería de la catedral de Burgos, obra encargada por él en $1516^{25}$.

Ambos lados de la capa se cierran con una pieza rectangular rematada en un broche de plata.

Iconográficamente la capa es la pieza de mayor interés, ya que el resto no presenta figuración. La protagonista clara de todo el conjunto es la Virgen, a cuya intervención en el nacimiento de Cristo se dedican las escenas de la cenefa, culminando el programa en el capillo, donde se representa la Asunción, una de las devociones particulares de Juan Rodríguez de Fonseca $^{26}$. La elección de escenas del ciclo del

25 En esta última obra el orifrés está decorado con capilletas rectangulares en las que aparecen figuras de santos, probablemente apóstoles, bajo su correspondiente arcuación, aunque el arco parece ser mixtilíneo, con un trazado más propio del gótico final.

26 El hospital de Toro, cuya construcción impulsó y a quien dejó el grueso de su herencia, se colocó bajo la advocación de la Asunción y los santos Juanes, su otra devoción particular de referencia. Sobre el hospital VASALLO TORANZO, Luis, Arquitectura en Toro (1500- 


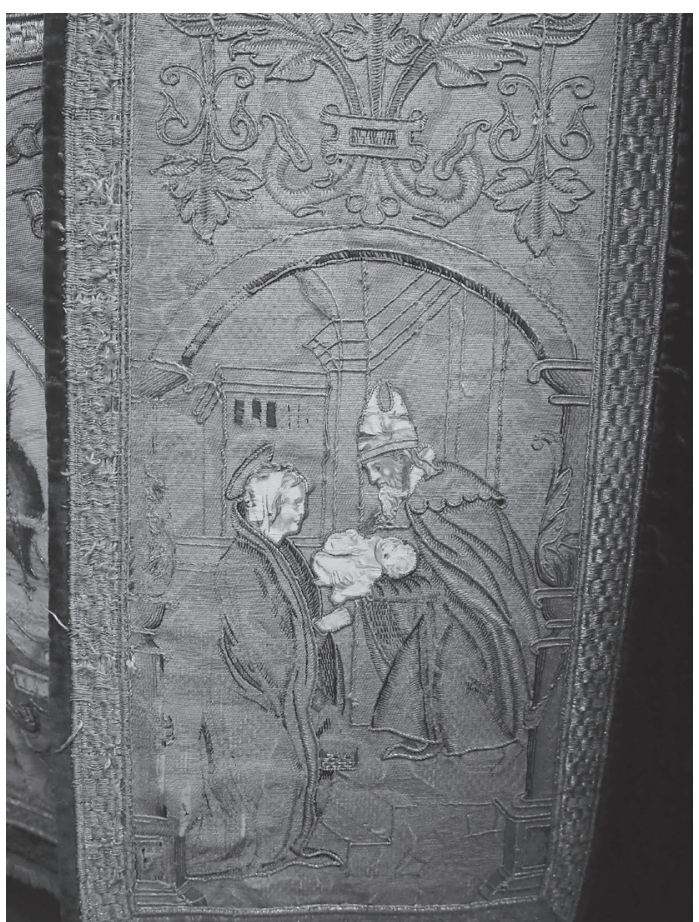

Fig. 3. Orifrés de la capa pluvial del terno de Juan Rodríguez de Fonseca. San Isidoro de León. Ca. 1525-1566. Foto de la autora.

nacimiento de Cristo obedece por un lado a la tradición canónica de los evangelios de Lucas y Mateo -Anunciación, Visitación, Nacimiento, Adoración de los Magos y Presentación- y por otra al habitual recurso a los apócrifos para otras escenas, como la Presentación de la Virgen (Protoevangelio de Santiago). Tanto esta última como la presentación del niño, apertura y cierre del ciclo iconográfico de la capa, introducen a la institución eclesiástica por medio de los sacerdotes del templo, lo que hace que sean una elección bastante adecuada en los ornamentos litúrgicos que portaban los celebrantes durante la liturgia. La Presentación del niño alude también a la circuncisión, momento en que fue derramada la primera sangre de Cristo, prefigura de la pasión y nexo, por lo tanto, con el sacrificio y redención, conceptos más propios de un terno carmesíi ${ }^{27}$.

1650), Instituto de Estudios Zamoranos "Florián de Ocampo", Zamora, 1994, pp.162-168.

27 La circuncisión se consideraba la primera estación de la pasión de Cristo y uno de los siete dolores de la Virgen, tema que se recoge también en el retablo homónimo que Fonseca donó a la catedral de Palencia y que puede verse en su trascoro. No hay que olvidar que el prelado perteneció a la cofradía de los Siete dolores de la Virgen de Bruselas desde 1504. GRANADOS SALINAS,
Las escenas representadas suelen utilizar una composición simple, de dos figuras enfrentadas en diversas posiciones. Únicamente la adoración de los magos presenta una composición más compleja al disponer un número mayor de personajes, siguiendo bastante de cerca un grabado de Martin Schongauer de la serie de la vida de la Virgen ${ }^{28}$. Ecos de Schongauer pueden verse también en otras escenas, como la de la Anunciación. Este referente compositivo un tanto retardatario (la estampa mencionada está fechada en 1482) se compensa con un enmarque, exactamente igual en cada escena, mucho más cercano a las formas renacentistas, formado por un arco muy rebajado que se apoya en dos columnas de medios -el superior abalaustrado- sobre plinto y con sencillo capitel toscano. Además, algunas escenas presentan en el fondo un marco arquitectónico de claro referente italiano, con perspectivas marcadas y formas clasicistas. Sobre el arco de remate encontramos un mismo motivo bordado con hojas que se curvan simétricamente a partir de un tarjetón, y de las que penden otras también de manera simétrica, elemento de claro origen renacentista.

En cuanto a las dalmáticas (Fig. 4), ambas idénticas, se hicieron también en terciopelo carmesí altibajo, decorándose los faldones, las bocamangas y el cuello, en este último caso con un estrecho collar que continua además por los jabastros que bajan por los laterales del cuerpo de la pieza, tal y como se dice en el testamento. Los materiales y técnicas son similares a los ya vistos para la capa, si bien los bordados son aquí más sencillos, tanto en materiales -más seda y menos oro- como en técnicas, reduciéndose en este caso los sobrepuestos, probablemente por la falta de figuración. Los motivos son vegetales y agrutescados y puramente renacentistas en su diseño -roleos, grutescos, cráteras-. Lo más destacable de ambas piezas es el faldón sobrepuesto en la parte inferior de anverso y reverso, una aplicación de gran tamaño -prácticamente igual en anchura a la propia dalmática-, de forma rectangular y for-

Rosario Inés, "Sorrows for a devout ambassador. A Netherlandish altarpiece in sixteenth century Castile”, en Potestas. Religión, poder y monarquía, 1, Castellón, 2008, pp. 101-129.

28 The illustrated Bartsch. 8. Early German artists, Abaris Books, New York, 1980, p. 217. El grabado fue copiado por Wenzel von Olmültz y Nicoletto da Modena, sin excesivas variantes compositivas. 


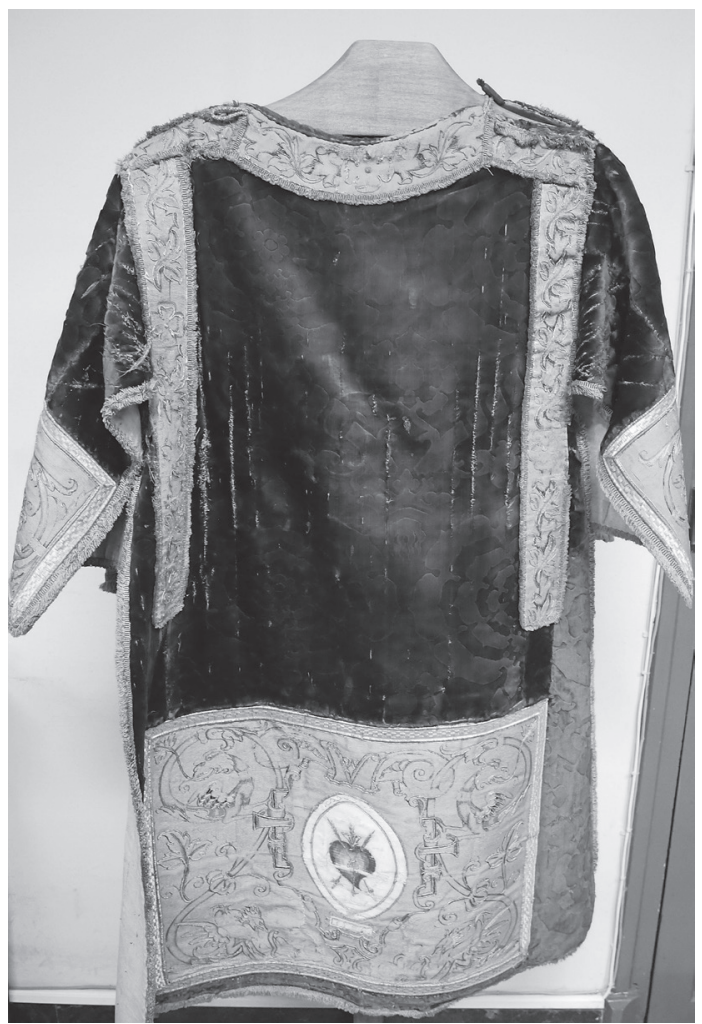

Fig. 4. Dalmática del terno de Juan Rodríguez de Fonseca. San Isidoro de León. Ca. 1525-1566. Foto de la autora.

mato apaisado, realizada, al igual que las partes principales de la capa pluvial, sobre tela dorada rematada con hilo de oro pasado en cuadrícula. Tanto en el anverso como en el reverso presenta un motivo central, sobrepuesto y enmarcado con motivos de cuero recortado, rodeado de elementos ornamentales bordados con distinto, aunque parecido, diseño. En el anverso el motivo es el emblema de la orden agustiniana -un corazón sangrante con tres flechas clavadas en su centro en un escudo ovalado, propio de la heráldica eclesiástica-, mientras en el reverso se reproduce el escudo del monasterio -campo clásico acabado en punta y cuartelado en cruz, con el primer cuartel barrado de cinco de oro y cuatro de plata; segundo de plata con tres coronas abiertas, una arriba y dos abajo; tercero con león rampante siniestrado con hacha y cuarto con león rampante ${ }^{29}$.

29 Similar a los que aparecen en diversos lugares de la colegiata, cambian aquí algunos de los colores, sobre todo de los fondos de los cuarteles, si bien es cierto que puede deberse al deterioro del bordado, ya que parece detectarse una cierta coloración negra (sable) en el fondo del primer cuartel y rojiza (gules) en el del segundo, así como algún tono dorado en el fondo del cuarto
Motivos similares a los de los faldones se repiten en las bocas de manga, con cráteras y cornucopias de las que surgen motivos de hojas y frutos. Hojas y tallos similares a los de estos elementos se repiten, con las mismas técnicas de bordado, en collares y jabastros.

La casulla (Fig. 5) se decora con una ancha cenefa sobrepuesta en vertical en su parte central, con motivos bordados en hilo de oro, y seda en tonos verdes, rojos y azules sobre un fondo blanco; los motivos son básicamente vegetales, con flores, palmetas y tallos enroscados además del escudo de los Fonseca muy destacado tanto en el anverso como en el reverso. En este caso no se utiliza el bordado sobrepuesto, con excepción del escudo, sino el bordado al pasado y el punto de matiz y el oro matizado.

El escudo obedece al modelo de cabeza de caballo, de oro con cinco estrellas de gules en sotuer y coronado por el tocado episcopal forrado de sinople, con cordones de seda rematados con borlas del mismo color, bajo el cual se encuentra la cruz de oro. El modelo de escudo es el que utilizó habitualmente Fonseca en sus últimos años y puede verse también en otras obras encargadas por él en sus últimos años, como la portada de Pellejería en la catedral de Burgos: un escudo de tradición italiana, con los bordes superiores enroscados a manera de pergamino, que enlaza tanto con la evolución de su gusto artístico al final de su vida hacia el modelo renacentista italiano, como con su interés por confirmar la antigüedad e importancia de su linaje.

El paño de facistol es sin duda la pieza más sencilla, lo que abona la hipótesis de una realización posterior, como complemento. Es una larga tira de terciopelo con los extremos decorados con un bordado sobrepuesto que reproduce el escudo de San Isidoro rodeado de tallos vegetales enroscados, el mismo motivo con que se rematan las dalmáticas.

Del análisis de las obras conservadas se desprenden las diferencias existentes entre la casulla y el resto de las piezas, tanto en las técnicas de bordado empleadas, como en los motivos formales e iconográficos, más cercanos éstos a la fecha de 1566 en la capa, dalmá-

frente a un fondo blanco (que debería ser de plata) en el tercero. Sobre la presencia del escudo de San Isidoro en la colegiata, aunque no recoge los del terno, ver CIMADEVILLA SÁNCHEZ, Pío, Repertorio heráldico leonés, Vol. III, 1, Instituto Leonés de Cultura, León, 2001, pp. 128-160. 


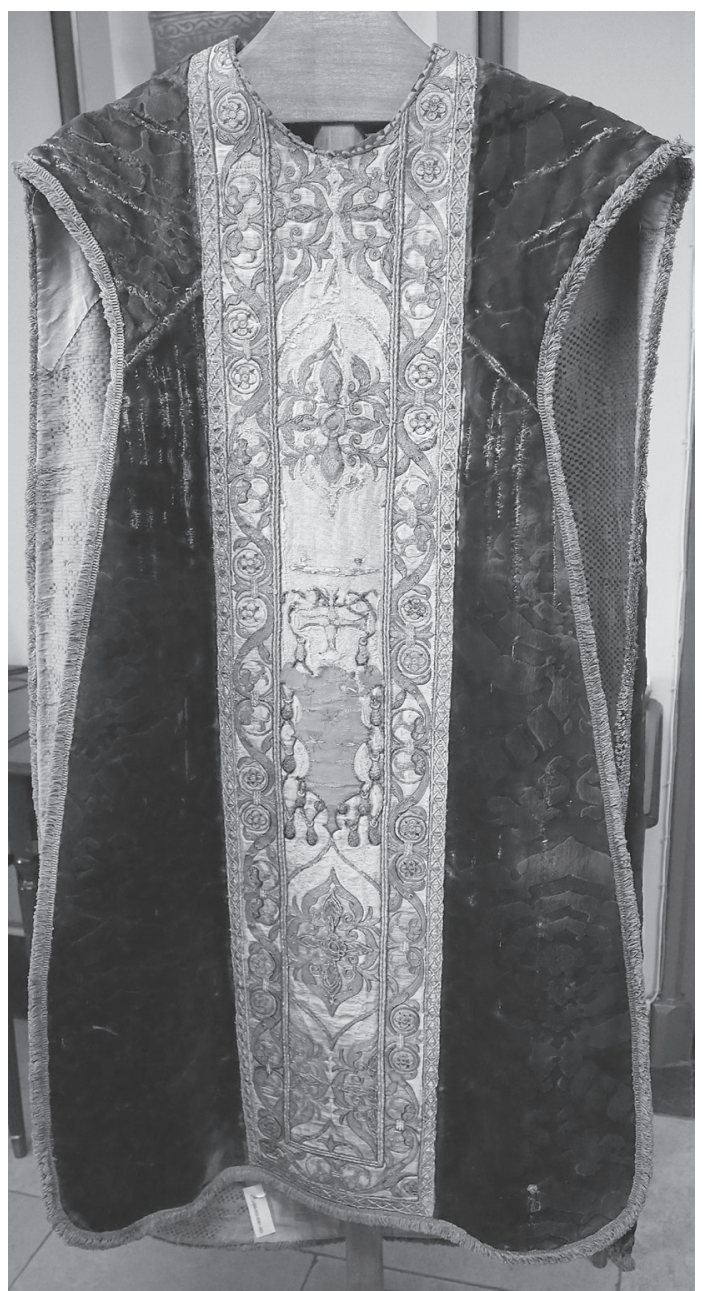

Fig. 5. Casulla del terno de Juan Rodriguez de Fonseca. San Isidoro de León. Ca. 1525-1566. Foto de la autora.

ticas y paños de facistol que al primer cuarto de siglo, cuando sabemos por el testamento de 1523 que las dalmáticas estarían ya terminadas. Teniendo en cuenta estos datos considero que podemos ver en la casulla el único resto directo del terno regalado por Fonseca a San Isidoro, siendo las dalmáticas bien una restauración de las originales -reaprovechando la base y sustituyendo faldones, bocamangas $\mathrm{y}$ jabastros y, por lo tanto, manteniendo la misma forma-, bien una sustitución completa de estas, aunque igualmente utilizando similares materiales y composición. Esta refacción de las dalmáticas, del tipo que fuera, parece haberse acompañado de la elaboración de la capa y el paño de facistol, lo que pudo haberse llevado a cabo en torno a la fecha de 1566 que aparece en las dalmáticas y en el paño. Ello explicaría la falta de los escudos del obispo en estas piezas, algo difícilmente comprensible en una obra por él encargada, dado el interés que puso en todas sus obras en dejar su huella personal por la vía de la heráldica; la presencia de los escudos de la orden agustiniana y del propio monasterio sería más lógica en una obra encargada por este último, lejos ya del recuerdo de Fonseca.

La diferencia de calidad es evidente entre la casulla y el resto. La cenefa de la casulla presenta un trabajo más minucioso y delicado, a pesar de la ausencia de figuración, en consonancia con lo que podría haber sido el legado de Juan Rodríguez de Fonseca, un patrón preocupado por la calidad artística y material de las piezas que encargaba y por la clara vinculación de estas con su nombre, si bien el destino de este legado a una casa por la que demostró un interés un tanto secundario no haría de ellas piezas de primerísima fila, como las que sí pudo ofrecer a las catedrales de Palencia o Burgos ${ }^{30}$. El monasterio, sin embargo, sí debió querer honrar a su abad, encargando el resto de piezas a un nivel similar al de las originales; se mantendría así el material de base y el color, así como la composición de las dalmáticas, añadiendo la capa y el paño de facistol, actualizando las nuevas piezas con técnicas y motivos más propios de mediados de siglo y poniendo un interés especial en la capa, que presenta una mayor calidad técnica $\mathrm{y}$ formal.

Con respecto a la autoría del conjunto no hay suficientes datos para poder concretar nombres. Al hablar del terno que deja en su testamento a la catedral de Córdoba cita a un tal Cornilles, que estaría haciendo la cenefa de la casulla. Puesto que en el momento de hacer el testamento Fonseca era obispo de Burgos podríamos deducir que sus encargos de ornamentos recaerían en bordadores burgaleses del momento, entre los cuáles encontramos, en 1521, a un Cornelis (o Cornieles) de Monte que trabajaba para la catedral y su obispo, obligándose a hacer, en este momento, una manga rica

\footnotetext{
30 En los ornamentos que regaló o legó a los templos con los que estuvo relacionado Fonseca guardó siempre un orden jerárquico que se manifestó en la cantidad y calidad de los mismos; de ese modo si a las catedrales dejó lujosos ornamentos completos, con sus frontales y otras piezas, a San Isidoro y Párraces dejó el terno básico -casulla y dalmáticas al primero, casulla, dalmáticas y capa al segundo-, y a otros monasterios -Palacios de Benaver y Ausín- sólo la casulla. Este criterio jerárquico se plasmó también en otras obras de su patronazgo.
} 
para el templo ${ }^{31}$. Evidentemente no podemos adjudicarle directamente la autoría ni del terno destinado a Córdoba ni, mucho menos, del terno de San Isidoro, si bien sería lo más lógico pensar que todas estas obras, incompletas en el momento de testar, y que no revestían para él un interés especial por hacer una obra destacable, se encargaran al mismo maestro o taller y que este fuera local.

En cuanto al resto del conjunto lo más probable es que se hiciera ya por encargo del monasterio. De hecho se conservan datos que indican la pobreza de ornamentos que vivía la casa en torno al mencionado año de 1566, en época del canónigo Durón, cuándo se compran un terno verde con tres albas a juego ${ }^{32}$, unas frontale$\operatorname{ras}^{33}$ y unas dalmáticas, además de arreglar otros ornamentos ya existentes ${ }^{34}$, todo ello en los términos más sencillos, dada la escasez de recursos que debía vivir la casa en aquel momento.

En este contexto, en noviembre de 1565, se había acordado comprar dos ornamentos, uno rojo y otro verde "que el señor prior lo concertase con algún casullero esta feria y se comprase aunque fuese fiado pues al presente no había dineros... Y el dicho señor prior dixo que él tenía tratado con un Gregorio de Valmaseda, vecino de Medina de Rioseco, que diese una guarnición para dos almáticas coloradas porque acá avía ya casulla, y otra guarnición para un terno entero verde, y que pedía por ello doscientos ducados. La guarnición avía de ser de peletado sobre tela de oro fino, conforme a una cenefa de casulla que traya el dicho Gregorio de Valmaseda a muestra, y que conforme a aquella hacía lo demás..."35. Quizá esta guarnición estuviera destinada a las dos dalmáticas rojas, que ya tenían casulla, del terno inicialmente legado por Fonseca, de hecho coincide la fecha, las piezas conservadas y su supuesta intervención, además de que la pobreza de la casa, que tuvo que recurrir a comprar de fiado, no parece compatible con el encargo de otro terno rojo diferente. Se confirmaría de este modo que del terno original quedaría la casulla que se conserva actualmente y, quizá, la base de las dalmáticas, modificadas en 1566 con la adición de la guarnición de Gregorio de Valmaseda. No hay, sin embargo, rastro documental de la capa y del paño de facistol, que quizá se encargaron en otro momento.
${ }_{31}$ BARRÓN GARCÍA, Aurelio, "Telas y bordados en Burgos durante el Renacimiento", en El siglo XVI en la ribera del Duero oriental. Arte, historia y patrimonio, Ayuntamiento de Aranda de Duero, Aranda de Duero, 2011, p. 90. MARTINEZ SANZ, Manuel, Historia del templo catedral de Burgos escrita con arreglo a documentos de su archivo, Imprenta de Anselmo Revilla, Burgos, 1866, p. 225, lo cita como bordador del obispo, es decir de Fonseca, en ese mismo año.

32 ASIL, Caja 74. Actas Capitulares 1548-1573, fol. 182v.

33 Ibídem, fol.187v. 31 de julio de 1566. Las frontaleras son "coloradas" y doradas. Las dalmáticas blancas y con los faldones bordados "para la casulla buena"

34 Ibídem. "A la casulla naranjada que se le ponga una cenefa bordada sobre azul, para que diga con la guarnición de las dalmáticas, y la que ahora tiene se ponga a la casulla verde, que es muy buena, y sirva la casulla y almáticas de comunes, porque el terno verde que ay común causa ynfamia dezir myssa con el". Además se acuerda comprar fundas para las casullas y capas que lo necesitaren para que estén "bien tratadas y duren más y se remiende todo lo que más estuviere mal tratado roto y descosido en la sacristía".
35 Ibidem, fol. 173v. 4 de noviembre de 1556 (sic) [1565]. El acuerdo se tomó en el aposento del prior, estando presentes varios canónigos, entre ellos Juan Durón. Al mismo Valmaseda se le compró "una tela de plata a manera de Damasco" para los faldones de unas dalmáticas que se estaban haciendo, que se completarían con casulla y capa de la misma tela en las que se pondrían "algunas cenefas viejas que ay en la sacristía buenas", fol.198r. 1 de julio de 1567. 